\title{
Development Strategies of Urban-rural Planning Management under New Situation
}

\author{
Fang Xu, Yong Ma \\ School of Law, Beihua University Jilin City, \\ Jilin Province, 132013
}

\begin{abstract}
In this paper, the new requirements for urban-rural planning management proposed in the Third Plenary Session of Eighteen have been discussed. It is advised that it is necessary to focus on the public interest, strengthen the supervision, improve the administrative transparency, improve the government efficiency and other related development strategies in urban-rural planning management so that some references can be provided for the reform of urban-rural planning management.

The "Decision of the CPC Central Committee on Comprehensively Deepening Reform of Several important Issues" (hereinafter referred to as the "Decision") ${ }^{1}$ proposed in the Third Plenary Session of Eighteen represents that China will conduct the deepest reform after reform and opening up, which is also related with the structural reforms of long-term development in our country and that has played an important role in urban-rural planning management.
\end{abstract}

\section{Keywords-urban-rural planning management; administration; reform \\ I. RElated Concepts Of URBan-RuRAl PlanNing MANAGEMENT}

The urban-rural planning refers to the important public policy that is adopted by government to regulate the urban-rural space resources and guide the urban-rural development and construction. The urban-rural planning management is one of the functions of urban-rural planning, the main work of which is to develop policies and regulations, approve the construction projects and coordinate with the construction practices. The main content of urban-rural planning management is to manage the planning and the approval of various construction projects and regulate the land and space utilization of construction projects. The main purpose of it is to protect the legitimate interests of construction personnel, safeguard the public interest and ensure that the various urban-rural construction activities should comply with the relevant laws, regulations, technical standards and planning documents.

\section{NEW REQUIREMENTS FOR URBAN-RURAL PLANNING MANAGEMENT UNDER NEW SITUATION}

In this "Decision", it is proposed that the new urbanization should be employed to promote the economic restructuring and expand the domestic demands. The main reform directions include four aspects, namely the land, the taxation, the finance and the household registration system.

\footnotetext{
${ }^{1}$ Communique of the Third Plenum of Eighteen of Communist Party, Xinhua News Agency, November 14, 2013.
}

The further reform has been proposed in the Third Plenary Session of Eighteen, which means that China's urban planning management is facing new changes. The innovative requirements of urban construction management requires to establish the transparent and standard urban construction financing mechanism, allows the local governments to broaden the urban construction financing channels through issue bonds and other ways and permits the social capital to participate in urban infrastructure investments and operations through franchising and other ways. At the same time, it is also required to build the urban infrastructure and residential financial institutions, improve the city standards and regulate the approval procedures. The counties which meet the adjustment conditions of administrative divisions can be orderly changed into cities. The rich towns which may absorb more population can be given the management rights compatible with the population and the economic scales. Among them, the urban-rural dual structure is the main obstacle to integrate the urban-rural development. In this "Decision", it is proposed that it is necessary to improve the institutional mechanisms and form the new industry-agriculture and urban-rural relationships in which industry promotes agriculture, urban areas can promote rural development, industry and agriculture reinforce each other and urban development and rural development are integrated. Some requirements are shown as follows: it is demanded to accelerate the construction of new agricultural management system, encourage the rural economic cooperation, give farmers more property rights and promote the equal exchange of urban-rural elements as well as the balanced allocation of public resources, etc. In order to further expand the new pattern of urban-rural development, firstly, it is needed to establish a comprehensive system of policies; secondly, it is necessary to promote the various policy reforms; finally, it is required to eliminate the barriers in institutional system and promote the reform innovation and institution building.

\section{REFORM STRATEGIES OF URBAN-RURAL PLANNING MANAGEMENT UNDER NEW SITUATION}

\section{A. Streamlining Administration, Delegating Power and Improving Government Efficiency}

The permission of urban-rural planning management should be improved towards the management decentralization, which can meet the development requirements of new urbanization. However, the distribution of administrative rights should not be overly 
dispersed. The whole-local relationship should be properly handled under the direction of macro control. At the same time, it is required to avoid the duplication and resource waste under the direction of resource concentration. It is necessary to focus on the social and environmental benefits, followed by the economic benefits. Meanwhile, it is also demanded to establish the mutual harmonized mechanism of inspection among areas. The urban-rural planning approval is a key part of urban-rural planning management rights, which is the interface between planning and implementation and that can directly affect the urban-rural planning and construction. The urban-rural planning approval is a complex multi-system, involving governments, developers and public, etc. In "Urban-rural Planning Laws", the graded approval, the pre-made review and the administrative decision-making have been arranged. Currently, the urban-rural planning approval must be determined by urban-rural governments and planning management departments. For each urban-rural planning management system, the top-down operation mechanism of urban-rural planning programs makes urban-rural planning and approval always flow in the government administration. With the development of socialist market economy, the contradiction between the existing approval system and the management is increasingly prominent due to the closed approval decision-making system, the rigid institutions, the inefficient "a book two cards" administrative licensing and the self-running approval management ${ }^{2}$. With the continuous progress of China's urbanization, it is required to explore the new urban-rural planning management patterns and work out a new path which meets the current development situation. In view of streamlining administration and delegating power, it is required to improve the planning approval levels, delegate the approval rights and improve the administrative efficiency. In order to improve the efficiency of urban-rural planning approval, it is necessary to improve the scientificity and the legality of urban-rural planning management. In the process of decision-making and approval, the digital urban information system can be adopted to improve the scientific degree of decision-making system.

\section{B. Coordinating the Interests Among Departments and Providing Services for Overall Interests of Planning}

In theexisting framework of administrative system, there are more than a dozen of administrative departments that have the rights to plan land and space. The Ministry of Construction and the Ministry of Land focus on land use; the National Development and Reform Commission and the Ministry of Industry and Information Technology focus on the economy and the industrial development; the environmental protection department, the water conservancy department and the transportation department stress on the special planning. As the planning programs

\footnotetext{
2 According to "Urban Planning Laws", the urban planning management employs the system in which the county planning and construction administrative department issues the site submissions, the construction land planning licenses and the construction planning licenses, namely "a book two cards".
}

among different departments are not comprehensively coordinated, the wide range of urban development planning can not be provided for urban development. Even it is difficult to establish the generally-applicable operating mechanism and reach a consensus through negotiation due to the conflict of interests. Then, the building practice is unable to obtain the efficient results. The urban-rural planning management is the comprehensive service-oriented work involved in all aspects, which demands the coordination and the assistance between departments as well as seeks for the support and the consensus between departments. In the process of planning, management and implementation, coordinating and organizing the works of various departments as well as rationalizing the relationship between various types of planning have become the prominent issues of government administration that demand to be solved in the reform process. The urban overall planning is to make the layout and the arrangement in space for the main road system of city, the infrastructure, the construction, the industry and other functional units as well as coordinate the spatial layout of various functions. The overall planning of city has a direct link with the overall planning of land use. However, as the overall planning of city and the overall planning of land use are prepared by departments with the same legal status, both of them are not attached to the relationship. They are converged with each other in some aspects. In the reform process of administrative system, the coordinating administrative operation is proposed. The most urgent requirement of urban-rural planning management is that the urban-rural planning departments and the departments of land resources should be coordinated to organize and prepare the overall planning of city and land use. The integration of overall planning of city and land use highlights the importance of "scale coordination" of urban development from the aspects of population and land size so as to ensure the consistency of urban development direction and key construction projects in the preparation period. In view of planning and preparation, it is required to establish the "two planning" 3 convergence land classification system and land targets. Then, the coordination of guiding ideology, planning period and construction projects is adopted to form the complete "two planning" convergence system. The convergence of "two planning" is the main way to improve the administrative management and the implementation efficiency under the reform requirements of administrative system.

\section{Strengthening the External Management and Building the Dual Supervision System}

The management supervision mainly includes internal and external systems: the management supervision work is mainly monitored by internal administrative system; the management of urban-rural planning is mainly monitored by external system through the methods of public show and review of Planning Board. Currently, the contradiction

\footnotetext{
3 “Two planning" refer to the overall planning of city and the overall planning of land use
} 
between urban-rural planning management and supervision becomes more prominent, including that the remarkable achievements affect the strategic planning, the urban expansion uses the dual system of land use and the vested stakeholders influence the urban development, etc. That is because of the inadequate administrative supervision mechanisms, the obstruction of urban-rural dualistic land system and the lack of social supervision management for stakeholders, etc. Therefore, the construction of internal and external supervision systems has become an important task for urban-rural planning management. Firstly, it is necessary to innovate the method of supervision management to optimize the internal system in the reform of administrative system. Through the reform measures of decision-making mechanism such as perfecting the social stability risk assessment mechanism of major decisions, innovating the administrative reconsideration system and improving the evaluation system of development results, it is required to change the adverse effects of remarkable achievements in planning strategies and correct the deviated achievements which take the economic growth as the target so as to promote the healthy development of urban-rural planning management. At the same time, through the establishment of integrated ecological civilization system, it is necessary to conduct the reform of dual system, change the land use status of urban construction and curb the behaviors of sacrificing rural interests, farmers' interests and environment to obtain the urban development in the process of urban expansion. It is demanded to build the urban-rural integrated development system. Secondly, it is needed to construct the power operation system with scientific decision-making, resolute implementation and effective supervision in view of the public interests. Meanwhile, it is also necessary to disclose the rights-running process and form the scientific and effective power control and coordination mechanisms. Moreover, it is required to introduce the social management supervision, form the effective external supervision management system and reduce the influence of vested stakeholders in the urban development process.

\section{Protecting the Citizens to Have the Right to be Informed and Improving the Administrative Transparency}

In "Urban-rural Planning Laws", the public participation is proposed. Although the existing public system and the urban-rural planning committee system have reduced the closed nature of urban-rural planning management to some extent and enhanced the transparency of urban-rural planning management, the available contradictions are still prominent.

The urban-rural planning committee is based on local regulations and operability of laws and planning. Currently, the urban-rural planning committees have been established in most cities. Due to the support of different laws and regulations and the limitation of decision-making right in operational levels, the urban-rural planning committee mainly includes three types, namely the consulting coordinating department, the legal considering department and the legal decision-making department ${ }^{4}$.

Although the formation and the functions of urban-rural planning committee are different, the main functions generally include studying the major principles and policies in urban-rural planning construction, coordinating the relationships in preparation, participating in the approval of urban planning and guiding as well as supervising the implementation of urban overall planning, etc. The urban-rural planning committee has built the bridge in which non-civil servants participate in the urban-rural planning management, which can promote the integration of technology decision-making and administrative decision-making and that can more objectively determine the public opinions. The participation of non-civil servants has ensured the public interests to some extent. However, due to the restriction of member election and groups of urban-rural planning committee, the public's collective choice can not be fully represented. Therefore, there also exist some limitations.

It is required to introduce the public to fully participate in the policy formulation and implementation process in multi dimensions so as to protect the public to have the right to be informed. Various publicity forms can be employed to change the passive public participation situation and establish the participant paths for public. For example, it is required to discuss with the public groups in planning process, strengthen the publicity of government affairs in approval process, promote the public supervision in implementation process, listen to the interest demands of public and ensure the public interests not to be infringed.

\section{CONCLUSION}

In short, China is in a new historical stage of building a moderately prosperous society and it enters into the critical period of institutional reform and social transformation. The various urban-rural construction activities should be conducted under the guidance of urban-rural planning management. In the background of new urbanization and reform of administrative system, the urban-rural planning management is required to make a positive response in the aspects of working efficiency, coordination of department interests and the democratization as well as the legislation of supervision system and management system so that they can meet the needs of social and economic development.

\section{REFERENCES}

[1] Communique of the Third Plenum of Eighteen of Communist Party, Xinhua News Agency, November 14, 2013.

[2] Guo Sujun. Thinking Over Urban Planning Decision-making System Reform From the Practice of Shenzhen. City Planning Review, 2009 (3).

\footnotetext{
${ }^{4}$ Guo Sujun. Thinking Over Urban Planning Decision-making System Reform From the Practice of Shenzhen. City Planning Review, 2009 (3).
} 